\title{
Adenoma Duplo da Paratireóide - Relato de Caso e Revisão da Literatura
}

\author{
Double Parathyroid Adenoma - a Case Report and Literature Review
}

\author{
Fábio Machado Landim', José Marconi Tavares², Marcelo Leite Vieira Costa ${ }^{3}$, Michelle Coelho Fontenele ${ }^{4}$, Roney Gonçalves Fechine Feitosa ${ }^{5}$
}

\section{Resumo}

O adenoma duplo da paratireóide (AD) é uma causa rara de hiperparatireoidismo primário (HPTP) que foi descrito pela primeira vez por Mandl em 1947. O hiperparatireoidismo primário é uma causa comum de distúrbio do metabolismo ósseo, envolvendo o aumento nos níveis circulantes de paratormônio (PTH), causado por adenoma, hiperplasia e, mais raramente, por carcinoma de paratireóide. A incidência do $\mathrm{AD}$, reportada em diversos estudos, varia de 3\% a $15 \%$ dos casos de hiperparatireoidismo primário. O trabalho tem como objetivo relatar um caso de adenoma duplo de paratireóide com revisão da literatura, no qual são abordados os diferentes aspectos do diagnóstico e do tratamento dessa doença. O diagnóstico de hiperparatireoidismo primário deve ser lembrado em todo paciente com nódulo palpável em região cervical, hipercalcemia e níveis elevados de PTH intacto $(>72 \mathrm{pg} / \mathrm{ml})$. O tratamento do paciente com suspeita de AD é a retirara das glândulas patologicamente aumentadas de volume e secretoras de hormônio através da cervicotomia.

Palavras-chave: Hiperparatireoidismo; Adenoma; Glândulas paratireóides

Serviço de Cirurgia do Hospital Geral Dr. Waldemar de Alcântara - Fortaleza (CE)

${ }^{1}$ Chefe do Serviço de Cirurgia do Hospital Geral Dr. Waldemar de Alcântara; Coordenador Geral da Residência Médica do Hospital do Câncer do Ceará

${ }^{2}$ Cirurgião do Hospital Geral Dr. Waldemar de Alcântara

${ }^{3}$ Cirurgiāo do Hospital Geral Dr. Waldemar de Alcântara

${ }^{4}$ Interna do Serviço de Cirurgia do Hospital Geral Dr. Waldemar de Alcântara

${ }^{5}$ Estagiário do Serviço de Cirurgia do Hospital Geral Dr. Waldemar de Alcântara

Endereço para correspondência: Dr. Fabio Machado Landim. Rua Deputado Moreira da Rocha 840 - apto 1700 - Meireles - Fortaleza (CE), Brasil, CEP: 60160060. E-mail: flandim@ibest.com.br 


\section{INTRODUÇÃO}

Adenoma duplo $(\mathrm{AD})$ da paratireóide é uma causa rara de hiperparatireoidismo primário (HPTP) que foi descrito pela primeira vez por Mandl em $1947^{1}$. Sua incidência reportada em diversos estudos varia de $3 \%$ a $15 \%$ dos casos de hiperparatireoidismo primário ${ }^{2,3}$.

O adenoma duplo é uma entidade patológica controversa para muitos estudiosos. Alguns estudos sugerem que o adenoma duplo não existe, sendo, na verdade, um caso de hiperplasia primária assimétrica da paratireóide ${ }^{4,5,6}$.

Apesar de essas pesquisas relatarem que o adenoma duplo de paratireóide é uma entidade patológica morfologicamente idêntica à hiperplasia de paratireóide, o adenoma duplo pode ser diferenciado por alguns aspectos clínicos, como a idade de acometimento da doença e a apresentação clínica ${ }^{7,8}$. É de fundamental importância o conhecimento acerca dessa diferenciação, uma vez que as condutas no tratamento e no prognóstico são distintas.

Os autores desse estudo apresentam um caso de adenoma duplo da paratireóide atendido no Hospital Geral Dr. Waldemar Alcântara (HGWA) com revisão da literatura sobre o tema, abordando os diferentes aspectos do diagnóstico e do tratamento dessa entidade nosológica.

\section{RELATO DO CASO}

Paciente de 44 anos, sexo feminino, admitida no HGWA em abril de 2007, com queixa de adinamia, perda ponderal de aproximadamente $10 \mathrm{~kg}$ em três meses, intolerância alimentar, febre ocasional e constipação intestinal. Foi atendida em vários serviços de emergência em ocasiōes distintas, sem resolução do quadro. Os familiares perceberam que a paciente, há 1 ano e 6 meses, vinha apresentando, progressivamente, distúrbios de comportamento, diminuição da memória e dificuldade de deambular. Nega etilismo, tabagismo e história mórbida familiar semelhante.

Ao exame físico, a paciente se encontrava em estado geral regular, desidratada $(+2 /+4)$, hipocorada $(+3 /+4)$, desorientada no tempo e no espaço. $P A=160 \mathrm{x}$ $90 \mathrm{mmHg} ; \mathrm{FR}=22 \mathrm{rpm} ; \mathrm{P}=90 \mathrm{bpm} ; \mathrm{T}=38^{\circ} \mathrm{C}$.

Palpação cervical: presença de nódulo na topografia da tireóide de consistência fibroelástica, pouco móvel à deglutição no lobo direito, e indolor, de aproximadamente $4 \mathrm{~cm}$. Observava-se ainda outro nódulo com as mesmas características no lobo superior esquerdo da tireóide com aproximadamente $1 \mathrm{~cm}$.

Exames pulmonar, cardíaco e abdominal sem sinais semiológicos patológicos.

Extremidades: pulsos periféricos palpáveis, sem edema.
Exames laboratoriais pré-operatórios: cálcio iônico $=$ $3,10 \mathrm{mmol} / \mathrm{L}$ (valor normal: $1,09-1,33$ ); fósforo $=3,6 \mathrm{mg} / \mathrm{dL}$ (valor normal: $2,5-4,5)$; albumina $=2,1 \mathrm{~g} / \mathrm{dL}$; creatinina $=$ $1,6 \mathrm{mg} / \mathrm{dL}$; paratormônio intacto $=1.411 \mathrm{pg} / \mathrm{mL}$ (normal até $72 \mathrm{pg} / \mathrm{ml}) ; \mathrm{TSH}=1,50 \mu \mathrm{U} / \mathrm{mL}$; hemoglobina $=10,8 \mathrm{~g} / \mathrm{dL}$; hematócrito em \% = 24,6 (36-48); calciúria de 24 horas $=6.430 \mathrm{mg} / 24 \mathrm{horas}$ (valor normal: 100-320). Exame qualitativo de urina com presença de esterases leucocitárias $(+++)$ e hemoglobina $(++)$. Sorologias infecciosas para Hepatites B e C, HIV e Pesquisa de BAAR no escarro negativas.

Foi iniciado cefepime após coleta de urocultura com intenção de tratamento empírico do quadro urinário.

A ecografia de glândula tireóide revelou presença de nódulos hiperecogênicos sólidos, heterogêneos, medindo $47 \times 22 \mathrm{~mm}$ e $18 \times 07 \mathrm{~mm}$, na topografia paratireóide à direita e à esquerda, respectivamente.

A paciente evoluiu com piora do quadro clínico, queda do estado geral, anasarca, acentuação do distúrbio psiquiátrico e impossibilidade de deambular, apesar do controle clínico com hidratação vigorosa, bifosfonados e corticoterapia. A densitometria óssea não foi realizada por piora clínica.

A paciente foi submetida a uma cervicotomia exploradora bilateral em caráter de urgência, cujos achados foram de nódulo de aproximadamente de 04 $\mathrm{cm}$ em paratireóide superior direita (Figura 1), bem definido e encapsulado, e nódulo de $1,5 \mathrm{~cm}$ em paratireóide superior esquerda (Figura 2). Realizado exame de ambas as paratireóides com análise anátomopatológica trans-operatória, revelando tratar-se de adenomas. O laudo histopatológico definitivo descreve macroscopicamente: peça ovalada, capsulada, elástica, de tecido pardo acastanhado, medindo $45 \times 40$ x $28 \mathrm{~mm}$ e pesando $10.000 \mathrm{mg}$ (Figura 3), e peça ovalada, capsulada, de tecido pardacento, medindo $12 \times 07 \times$ $04 \mathrm{~mm}$ e pesando $260 \mathrm{mg}$ (Figura 4). O exame microscópio das peças e de suas congelações foram compatíveis com neoplasia de glândula paratireóide composta por células de citoplasma predominantemente claro, eosinofílico, formando túbulos interconectantes e folículos com estroma vascularizado, com áreas de fibrose e hemossiderófagos. Conclusão: Adenoma (02) múltiplo de paratireóide, consistente com adenoma de células principais.

Avaliação laboratorial do $15^{\circ}$ dia do pós-operatório apresentou: cálcio iônico $=1,10 \mathrm{mmol} / 1$; creatinina $=$ $0,9 \mathrm{mg} / \mathrm{dL}$; albumina $=2,1 \mathrm{~g} / \mathrm{dl}$; paratormônio intacto $=$ $110 \mathrm{pg} / \mathrm{mL}$ (normal até 72 ); hemoglobina $=8,8 \mathrm{~g} / \mathrm{dL}$; hematócrito em $\%=29,8$; cálcio sérico $=7,5 \mathrm{mg} / \mathrm{dl}$; potássio $=3,5 \mathrm{mmol} / 1$. No $21^{\circ}$ dia do pós-operatório, paciente se encontrava consciente, orientada no tempo e no espaço, verbalizando, deambulando e com ganho ponderal. 


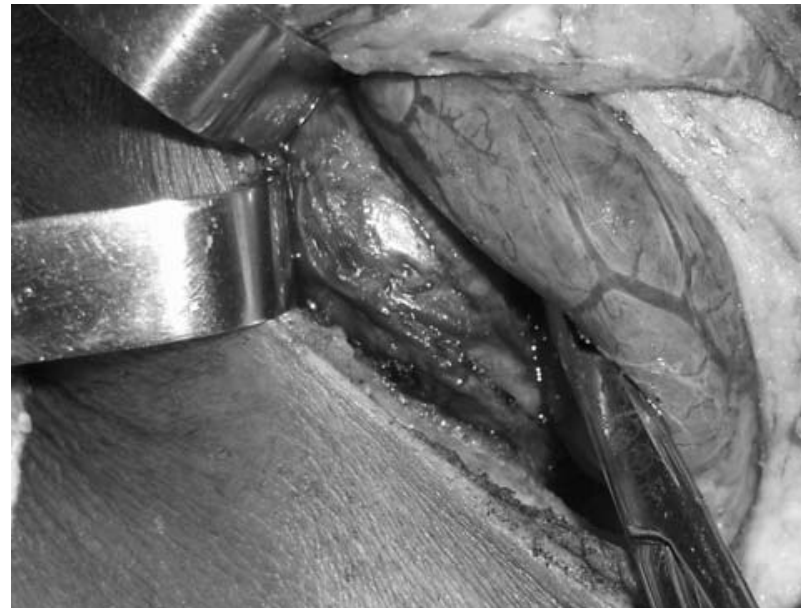

Figura 1. Adenoma da paratireóide superior direita $\operatorname{com~} 04 \mathrm{~cm}$, lobo tireoidiano direito anteriormente

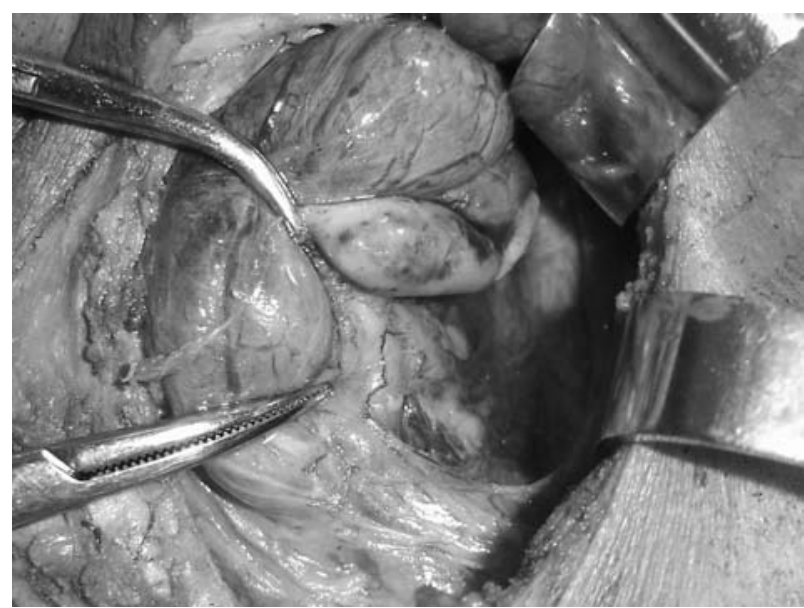

Figura 2. Adenoma da paratireóide superior esquerda com $04 \mathrm{~cm}$, lobo tireoidiano esquerdo anteriormente

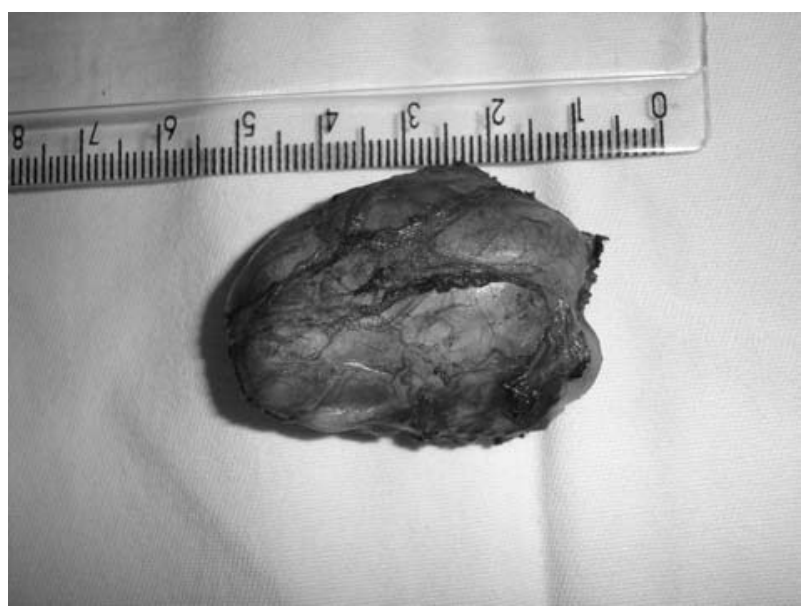

Figura 3. Peça da paratireóide superior direita

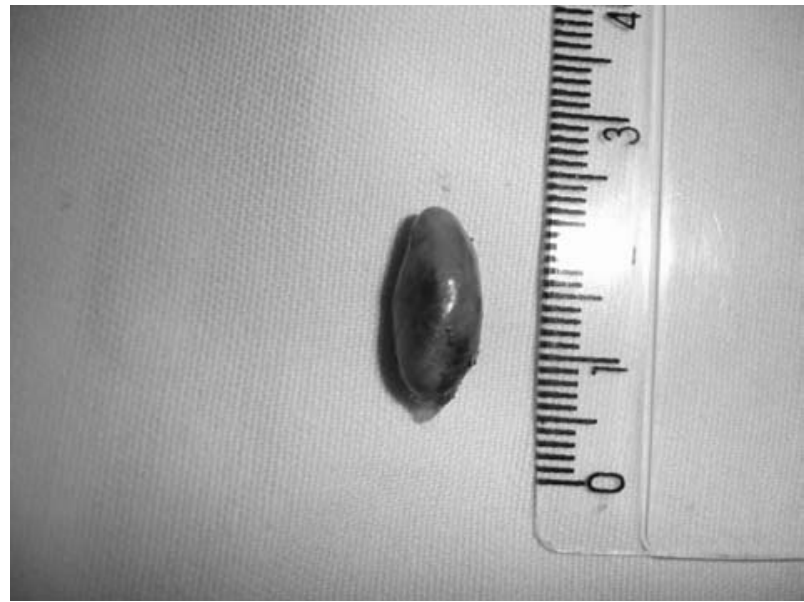

Figura 4. Peça da paratireóide superior esquerda

\section{DISCUSSÃO}

O adenoma duplo da paratireóide é uma causa rara de hiperparatireoidismo primário (HPTP) que foi descrito pela primeira vez por Mandl em $1947^{1}$. Sua incidência vem variando ao longo dos anos, sendo mais prevalente no sexo feminino e na faixa etária maior de 60 anos $^{8}$. Na década de 1980, alguns trabalhos ${ }^{9,10,11}$ reportaram incidência da doença em torno de $3 \%$. Na década de 1990, a incidência era de aproximadamente $8 \%{ }^{7,8,12}$. E, mais recentemente, a incidência apontada pela literatura científica é de $15 \%{ }^{13}$. Desde sua descoberta, o $\mathrm{AD}$ gerou controvérsia quanto à sua real existência como entidade patológica distinta de HPTP. Durante décadas, diversos pesquisadores buscaram padrōes histológicos, que diferenciassem o adenoma da hiperplasia da paratireóide $e^{5,11,14,15}$. Não obstante, os padrōes histológicos apontados foram incapazes de distinguir morfologicamente essas patologias.

Em meados do século XX, muitos trabalhos foram realizados com objetivos de identificar marcadores, através da biologia molecular, para avaliar a "clonalidade" das glândulas paratireóide anormais ${ }^{16,17,18}$. Sugeriu-se a hipótese de que a hiperplasia era um evento policlonal, enquanto o adenoma, monoclonal. Diferenciação policlonal ocorre quando uma doença se origina de vários "clones" celulares distintos, enquanto uma patologia monoclonal ocorre quando a enfermidade surge após diferenciação e promoção de um "clone" unicelular. Por conseguinte, o $\mathrm{AD}$ seria um evento raríssimo, tendo em vista que seriam necessários dois eventos monoclonais em locais distintos. Porém a incidência do $\mathrm{AD}$, já relatada, não é tão baixa, levando os pesquisadores a pensarem em outras hipóteses.

Milas et al. ${ }^{13}$ e Bergson e Heller ${ }^{19}$ reportaram em suas séries que o $\mathrm{AD}$ apresentava predileção pela 
distribuição bilateral superior. As paratireóides superiores têm origem embrionária do quarto arco branquial, sugerindo-se que o $A D$ possa ser uma manifestação de hiperplasia de paratireóide originada do quarto arco branquial (doença da quarta bolsa branquial, ao invés de um raro evento neoplásico isolado e independente, em dois locais diferentes). Isso explica a incidência da doença reportada nos estudos acima.

Os sintomas do paciente com $\mathrm{AD}$ estão relacionados com a intensidade da hipercalcemia. A hipercalcemia extrema leva a sintomas típicos como as manifestaçōes neurológicas (confusão mental, letargia, fraqueza, hiperreflexia, ou coma nos casos graves), gastrintestinais (dispepsia, constipação, anorexia, náusea e vômito), geniturinárias (poliúria, polidipsia e nefrocalcinose) e cardiovasculares (hipertensão arterial e alterações de ritmo cardíaco). Parece que o $\mathrm{AD}$ apresenta mais manifestaçôes neuromusculares como: fadiga, fraqueza e dor óssea, do que as outras causas de HPTP ${ }^{17}$. Em geral, a necessidade de tratamento de urgência ocorre quando o nível sérico de cálcio está acima de $14 \mathrm{mg} / \mathrm{dl}$.

A presença de nódulo palpável em região cervical, hipercalcemia e níveis elevados de PTH intacto $(>72 \mathrm{pg} / \mathrm{ml})$ fecham o diagnóstico de hiperparatireoidismo primário.

A avaliação laboratorial do paciente com HPTP, com hipercalcemia grave em urgência, deve incluir: cálcio iônico, fósforo, creatinina, sódio, potássio, hemograma, gasometria, amilase e eletrocardiograma. Uma amostra de PTH sérico deve ser colhida antes do início do tratamento e será de grande valia para o diagnóstico diferencial do paciente.

A dificuldade em diferenciar adenoma de hiperplasia na análise histológica tem resultado em diferentes recomendaçōes sobre o manejo cirúrgico adequado do HPTP. Por conseguinte, em 1970, propôs-se a realização de paratireoidectomia subtotal em todos os pacientes com HPTP, pois se temia que a hiperplasia fosse subdiagnosticada e tratada de uma maneira ineficaz ${ }^{20}$. Estudo de $1990^{2}$ criticou a rotina de paratireoidectomia subtotal e preconizou a cervicotomia bilateral com remoção de somente as glândulas macroscopicamente aumentadas, relatando um erro de apenas 2,2\%, usando esse método. As paratireóides, normalmente, sem patologia, pesam em média 28 a $33 \mathrm{mg}$ e suas dimensōes podem atingir um valor limite de 7 x 5 x $2 \mathrm{~mm}$ geralmente com aspecto ovalado ${ }^{13}$. A identificação do $\mathrm{AD}$ depende da habilidade do cirurgião e do patologista em distinguir adenomas e hiperplasia de glândulas. Parâmetros macroscópicos da glândula, como o tamanho, podem ser utilizados pelo cirurgiāo durante $\mathrm{o}$ ato operatório para facilitar a identificação das glândulas anormais. No presente trabalho, os adenomas pesaram $10.000 \mathrm{mg}$ e $260 \mathrm{mg}$ com medidas de $45 \times 40 \times 28 \mathrm{~mm}$ e $12 \times 07 \times 04 \mathrm{~mm}$, respectivamente, dimensōes bem acima dos descritos na literatura.
Avanços recentes no manejo do HPTP se deram com a medida do PTH intra-operatório e com a cintilografia das paratireóides com Sestamibi-Tc99m. Em 1998, o advento do uso da medida do PTH durante a operação de paratireóide (IOPTH) providenciou um recurso adicional para assegurar uma adequada paratireoidectomia ${ }^{21}$. Irvin et al. ${ }^{22}$ estabeleceram parâmetros para seu uso como um indicador da paratireoidectomia. A dosagem do PTH intra-operatório $(10-5 \mathrm{pg} / \mathrm{mL})$ permite uma avaliação acurada da qualidade da ressecção no momento do ato cirúrgico, diminuindo a ocorrência de hipercalcemia pós-operatória ${ }^{23,24}$. Outro grande avanço no tratamento do HPTP foi a cintilografia das glândulas paratireóides com Sestamibi-Tc99m ${ }^{25,26}$. Com essa técnica, o cirurgião pode realizar a exploração cirúrgica unilateral da região cervical, através do mapeamento da(s) glândula(s) antes do início do ato operatório, permitindo uma redução do tempo de cirurgia e internação, bem como uma menor morbidade pós-operatória ${ }^{25,26}$. No entanto também poderá gerar hipercalcemia persistente póstratamento, tendo em vista que o exame unilateral cervical renderá somente metade da história e, por conseguinte, o tratamento será incompleto.

Conclui-se que, na atual realidade brasileira de dificuldade de acesso à tecnologia na saúde (cintilografia das paratireóides e dosagem rápida do $\mathrm{PTH}$ ), o adenoma duplo da paratireóide pode ser tratado com segurança através da exploração cervical bilateral das paratireóides com alta efetividade, alcançando índices de cura de até $98 \%$, dependendo da experiência do cirurgião. O prognóstico é excelente quando diagnosticado e tratado adequadamente, com baixos índices de recidiva ${ }^{24}$.

\section{REFERÊNCIAS}

1. Mandl F. Hyperparathyroidism: are views of historical development sand the present state of knowledge on the subject. Surgery. 1947;21:394-440.

2. Attie JN, Bock G, Auguste LJ. Multiple parathyroid adenomas: report of thirty-three cases. Surgery. 1990;108(6):1014-20.

3. Udelsman R. Six hundred fifty-six consecutive explorations for primary hyperparathyroidism. Ann Surg. 2002;235(5):665-72.

4. Block MA, Frame B, Jackson CE. The efficiency of subtotal parathyroidectomy primary for hyperparathyroidism due to multiple gland involvement. Surg Gynecol Obstet. 1978;147(1)1-5.

5. Ghandur-Mnaymneh L, Kimura N. The parathyroid adenoma. A histopathologic definition with a study of 172 cases of primary hyperparathyroidism. Am J Pathol. 1984;115(1):70-83.

6. Wang CA, Rieder SV. A density test for the intraoperative differentiation of parathyroid hyperplasia from neoplasia. Ann Surg. 1978;187(1):63-7. 
7. Bartsch D, Nies C, Hasse C, Willuhn J, Rothmund M. Clinical and surgical aspects of double adenoma in patients with primary hyperparathyroidism. Br J Surg. 1995;82(7):926-9.

8. Tezelman S, Shen W, Shaver JK, Siperstein AE, Duh QY, Klein H, et al. Double parathyroid adenomas. Clinical and biochemical characteristics before and after parathyroidectomy. Ann Surg. 1993;218(3):300-7; discussion 307-9.

9. Hines JR, Atiyah R, Kliefoth J, Beal JM. Hyperparathyroidism: problems in surgical management. Am J Surg. 1982;144(5):504-10.

10. Thompson NW, Eckhauser FE, Harness JK. The anatomy of primary hyperparathyroidism. Surgery. 1982;92(5):814-21.

11. Verdonk CA, Edis AJ. Parathyroid "double adenomas": fact or fiction? Surgery. 1981;90(3):523-6.

12. Roses DF, Karp NS, Sudarsky LA, Valensi QJ, Rosen RJ, Blum M. Primary hyperparathyroidism associated with two enlarged parathyroid glands. Arch Surg. 1989;124(11):1261-5.

13. Milas M, Wagner K, Easley KA, Siperstein A, Weber CJ. Double adenomas revisited: nonuniform distribution favors enlarged superior parathyroids (fourth pouch disease). Surgery. 2003;134(6):995-1003; discussion 1003-4.

14. Harness JK, Ramsburg SR, Nishiyama RH, Thompson NW. Multiple adenomas of the parathyroids: do they exist? Arch Surg. 1979;114(4):468-74.

15. Wells SA Jr, Leight GS, Hensley M, Dilley WG. Hyperparathyroidism associated with the enlargement of two or three parathyroid glands. Ann Surg. 1985;202(5):533-8.

16. Arnold A, Staunton CE, Kim HG, Gaz RD, Kronenberg HM. Monoclonality and abnormal parathyroid hormone genes in parathyroid adenomas. $\mathrm{N}$ Engl J Med. 1988;318(11):658-62.
17. Jackson CE, Cerny JC, Block MA, Fialkow PJ. Probable clonal origin of aldosteronomas versus multicellular origin of parathyroid "adenomas". Surgery. 1982;92(5):875-9.

18. Larian B, Alavi S, Roesler J, Namazie A, Blackwell K, Calcaterra TC, et al. The role of hyperplasia in multiple parathyroid adenomas. Head Neck. 2001;23(2):134-9.

19. Bergson EJ, Heller KS. The clinical significance and anatomic distribution of parathyroid double adenomas. J Am Coll Surg. 2004;198(2):185-9.

20. Haff RC, Ballinger WF. Causes of recurrent hypercalcemia after parathyroidectomy for primary hyperparathyroidism. Ann Surg. 1971;173(6):884-91.

21. Nussbaum SR, Thompson AR, Hutcheson KA, Gaz RD, Wang CA. Intraoperative measurement of parathyroid hormone in the surgical management of hyperparathyroidism. Surgery. 1988;104(6):1121-7.

22. Irvin GL 3rd, Dembrow VD, Prudhomme DL. Clinical usefullness of an intraoperative "quick parathyroid hormone" assay. Surgery. 1993;114(6):1019-23.

23. Chen H, Pruhs Z, Starling JR, Mack E. Intraoperative parathyroid hormone testing improves cure rates in patients undergoing minimally invasive parathyroidectomy. Surgery. 2005;138(4):583-7; discussion 587-90.

24. Gil-Cárdenas A, Gamino R, Reza A, Pantoja JP, Herrera MF. Is intraoperative parathyroid hormone assay mandatory for the success of targeted parathyroidectomy? J Am Coll Surg. 2007;204(2):286-90.

25. Calva-Cerqueira D, Smith BJ, Hostetler ML, Lal G, Menda Y, O'Dorisio TM, et al. Minimally invasive parathyroidectomy and preoperative MIBI scans: correlation of gland weight and preoperative PTH. J Am Coll of Surg. 2007;205 (4 Suppl 1):S38-44.

26. Lo CY, Lang BH, Chan WF, Kung AWC, Lam KSL. A prospective evaluation of preoperative localization by technetium-99m sestamibi scintigraphy and ultrasonography in primary hyperparathyroidism. Am J Surg. 2007;193(2):155-9.

\section{Abstract}

Double adenoma (DA) of the parathyroid is a rare cause of primary hyperparathyroidism (PHPT), described for the first time by Mandl in 1947. PHPT is a common cause of disorders of bone metabolism, involving increased serum parathyroid hormone (PTH) levels, caused by adenoma, hyperplasia, and more rarely by parathyroid carcinoma. DA incidence as reported in several studies varies from $3 \%$ to $15 \%$ among cases of PHPT. The objective of this study was to report a case of double adenoma of the parathyroid, accompanied by a literature review. The authors describe the different aspects of diagnosis and treatment of this disease. A diagnosis of hyperparathyroidism should be considered in all patients with palpable cervical nodule, hypercalcemia, and elevated intact PTH $(>72 \mathrm{pg} / \mathrm{ml})$. Treatment of patients with suspected DA involves removal of the pathologically enlarged glands by cervicotomy.

Key words: Hyperparathyroidism; Adenoma; Parathyroid glands 